\title{
Cornell's Reclassification Program
}

By FELIX REICHMANN

$\mathrm{C}$ ORNELL's first president, Andrew D. White, was a scholar, a bibliophile, and a man of independent means-an ideal combination for a university president. Under his patronage the library of the young institution grew quickly to eminence. By 1890, Cornell University library ranked fourth in size among American university libraries. With the beginning of the twentieth century, however, the halcyon days of the library had passed and the two storm clouds gathered -inadequate financial support and insufficient shelving space-clouds that would darken the life of the institution for the next half-century. Because of these adverse circumstances, the library could not make the necessary adjustments, keep up with the rapid development of her more fortunate sister institutions, and adopt modern methods of library administration, but struggled instead in the quagmire of an obsolete building and antiquated procedures.

The biggest stumbling block to the modernization of the library's technical operations was its outdated classification system. What is locally known as the "Harris classification" is a system of shelf numbers which follows a loose systematic arrangement satisfactory for a closedshelf library. First adopted by the British Museum in 1836, it had the nimbus of scholarly respectability and had been applied to the Cornell University holdings by the librarian, George W. Harris, in 1891. Maurice Tauber has succinctly characterized this shelf scheme:

The Harris scheme is not a genuine subject classification, but a fixed location device. It has not been revised and
Mr. Reichmann is Assistant Director, Cornell University Libraries.

adapted to fit modern needs as have other systems such as that of the Library of Congress. It is not taught in library schools and it is not used in any other major American library. Only after considerable study and experience is it possible to gain some insight into the peculiar characteristics of the complex system but even then consistency is not possible, since the classification, long outdated and inflexible, contains too many inherent inconsistencies.

Before the first World War, Cornell librarians realized the necessity of replacing the "Harris classification" with a modern scheme. In 1916 the Annual Report mentions the "few changes which are necessary to make the [card catalog] conform to the latest practice in library economy." The report clearly indicates the intention of the administration to modernize the procedures, although at a slow pace:

Cornell University Library was begun before the days of modern library economy and as much of the work in such a library is cumulative in characteristic, it is not possible to suddenly put into operation more modern methods. For this reason only such changes have been attempted as could easily be made without disturbing the working efficiency of the library.

In 1918 (no report was issued for 1917) the "few changes of 1916" were specified:

The work of reclassifying the Spanish and Portuguese languages and literature 
in accordance with the Library of Congress system of classification (modified) has been completed.

From this date on, year after year the Annual Report identifies the slow steps taken to reclassify the collection. In 1919 the report reads:

During the year the books dealing with the European war have been reclassified according to the Library of Congress system, thus providing for a more comprehensive collection than could have been included under the old system. The Scaife collection (Civil War literature) has also been classified by the Library of Congress system and the works dealing with the same subjects that were already in the library will be reclassified and shelved with them.

In 1920 the reclassification of the Prudence Risley Hall library (a small library in a girls' dormitory) is mentioned. In 1921 the periodicals of the Wason collection (books in Western European languages on China) were classified, and in 1922 a new head of the catalog department, Emma Runner, was brought from the Library of Congress probably with the intention of speeding up the reclassification. In 1927 the library proudly reports:

The Library of Congress system of classication is being gradually substituted for the old method of marking books to a definite place, in use since occupying the present building. At the present time, the Library of Congress system is being used for the open shelf books, general periodicals, encyclopedias, Spanish literature, Van Cleef (zoology), Gray Library (electrical engineering), Agriculture College Library, Wason Chinese Collection and Free Masonry.

In 1929, Mr. Austin's last report as librarian, the reclassification work is summed up:

The next step after accessions in making library materials available for use is classification. In 1891 when the books were moved to the present building and some system of numbering was necessary to keep them in order on the shelves, no scholarly or really adequate system of classification adapted to the needs of a large university library had been worked out. A modified British $\mathrm{Mu}$ seum system of notation was adopted as the best means of keeping materials in order, although it could not in any sense be said to classify the books. The inherent weaknesses of this system have been more and more in evidence with the growth of the library.

The labor of re-marking the accumulated materials according to a later and better system was too great to undertake all at once. The need for working space and funds for additional workers was so great in 1915 that it did not seem feasible to undertake it. Therefore, additions to the groups of books already in the library were continued with the same system of marking, because it was feared that confusion and therefore some interference with the use of books might result from the use of two systems in the same group. All new groups, however, and some smaller units already in the library, have been classified by the system devised by the Library of Congress which is the best system of classification known to the library world. The open shelf and reference books were the first to be thus classified. Then the cyclopedias and general periodical literature were dealt with and brought together in a more convenient location for ready consultation.

The most important step in adopting a new system of classification has been made in connection with the new distinct collections added during this period. The Agricultural College Library books, when removed from the general library were classified by the Library of Congress method. The division of Spanish Literature, the Scaife Collection of American History, the Van Cleef Medical Library, and the Gray Memorial Library have all been classified by the $\mathrm{Li}$ brary of Congress system, with certain modifications. The large Wason collec- 
tion, dealing with China and the Chinese, the Loewy Collection of Free Masonry, and the mathematical books deposited in White Hall, having been brought together within recent years, have all been classified by the Library of Congress system. Arrangements are under way to reclassify the Barnes Library of Religious Literature to bring it in line with modern system.

This was the swan song of Cornell's first attempt at reclassification. It was not successful because it was too cautious. It never gathered enough momentum to get off the ground; it just faded out, and the great problems of the 1930's buried it under the sand of oblivion. Moreover, it did not break resolutely with the old system. The Library of Congress classification was accepted with important homemade adaptations, changes which nullified almost all the advantages which could have been gained. Fortunately, some college libraries which were not at that time under the administration of the university library had accepted (or did accept shortly) the correct Library of Congress classification (Agriculture, Engineering, Architecture); also, the classification and most of the cataloging of the Wason Collection could be interfiled without changes when eighteen years later the second-and this time, successful-effort was made to modernize Cornell University library's technical procedures.

The space problem was the reason that the question of reclassification disappeared from the Annual Reports of the library after 1929. The library building was so overcrowded that there was not enough space for books, readers, or staff. The very usefulness of the library was in jeopardy. Even as a dead storage building it would not have been acceptable as the closely packed shelves did considerable damage to bindings. The building with its tower, a landmark for the Cornell campus, had been erected in 1891 and had been justly considered one of the best library structures at that time. The capacity was calculated to be four hundred thousand volumes, (later experience proved that this figure was too optimistic and that three hundred forty thousand was more nearly correct) a generous size for a collection of about one hundred thousand volumes. Under the impact of rapid increase in library holdings, both by purchase and by gift, (the Fiske gift embracing three world-famous collections-Petrarch, Dante, and Icelandicawas received in 1893 and 1905) the available shelf space shrank swiftly, and reached a dangerous low in 1910. The Annual Report for that year mentions that the growth of the library had resulted in congestion in many places: "79 per cent of the space is actually filled, and in the Andrew D. White Library (history) 88 per cent is filled." Mr. Harris concludes his report with the statement:

The overcrowding of the shelves has begun to be felt .... thus decreasing the usefulness of the library. I, therefore, respectfully urge that immediate provision be made for additional shelf room to relieve the congestion.

Only some patchwork had been done twenty years later. In the meantime, the situation had become unbearable because holdings exceeded the calculated capacity by about 75 per cent. There was simply no space anywhere for anything. The Faculty Library Committee, which was in charge before the new librarian, Otto Kinkeldey, could take over, discussed the problem and came to the following conclusion:

All plans mentioned are mere makeshifts and palliatives. The Committee has at every point been brought face to face with the fact that it is not in such fashion that the Library can fulfill its duty to the University. We think that the time for patching up the Library building has gone by, and that the trustees and the faculty ought at once to recognize the Library's problem as one demanding heroic treatment. 
Dr. Kinkeldey took the lead from this prologue to his administration, and in sixteen long and frustrating years he hammered into trustees, administration, and faculty the need for a new building. His annual reports form the most pathetic pages in American library history and testify to his understanding of the problems which confronted him and to the courage and tenacity with which he tried to solve them. Skillfully, he used all the means which his keen intelligence and vast erudition had put at his disposal. In fifteen variations upon the central theme "inadequate," he cajoled, implored, and threatened; he was factual, ironical, sophisticated, and blunt. Like the "eloquent peasant" he found new mutations to his leitmotiv. The Egyptian story of the eloquent peasant had a happy ending. The Pharaoh was so pleased with the eloquence of the peasant's first complaint that he postponed his decision to elicit further epistles but finally granted the reward; for Dr. Kinkeldey, however, the authorities remained mute.

The "compression nightmare," as he called the library building, is well illustrated in the Annual Report of 1933:

In the meantime we may console ourselves with the thought that the Library has proved itself entirely modern in its failure to conform to the accepted laws of physics. In these days of non-Euclidean geometry, non-Aristotelian logic and non-Newtonian physics it is not surprising to find that a space fully occupied could absorb a substantial addition to its contents. Located in the Cornell University Library King James' full tub of water will not overflow upon the addition of the fish. In the coming year the absolutely filled building will have to accommodate the next increment in the same way. The relativity theorists will have to find a place in their system for the concept of complete fullness. We are demonstrating the theorem that two bodies, when they take the form of books or of library workers, can occupy the same space.
Aside from the compression nightmare, and with due allowance for the prevalent shrinkage of incomes, the Library has flourished and functioned as well as might reasonably be expected in its present condition.

In 1935 he recapitulated briefly the story of the building and compared the estimate of the builder with the actual holdings and concluded:

[We were forced to resort] to a system of compression and congestion which, as has been repeatedly pointed out in $\mathrm{Li}$ brarians' reports, not only hampers the proper functioning of a library with respect to its users but is actually harmful to the book and bindings entrusted to our care. For this condition there is but one real remedy-a new library building, which would also provide proper working space for the technical staff required for a collection of this size.

In 1936 he acknowledges "with joyous gratitude" the plan of a small annex in the southwest corner of the building (holding about one hundred ten-thousand volumes) but concludes:

The Librarian ventures to repeat a statement made in his last report. An adequate provision for book space and work space required by a collection as large as ours, with facilities commensurate with the size and importance of the University, can be made only in a new, modern library building.

Year for year the story is repeated. Thus, in 1941 Dr. Kinkeldey burst out:

As has been pointed out in all reports of recent years, the problem of housing and handling the growing book collection becomes more and more serious. It is the Librarian's fervent hope and prayer that the consideration of increased space ... will not be delayed ... and that the even more pressing problem of working space for a harassed staff will be solved in the not too distant future.

In 1944 another approach is attempted 
using the terminology of the second World War:

The Germans have made us familiar with the problem of the lebensraum but they have no monopoly or vested right in this idea. ... We at Cornell come close to a demonstration that two or more staff members can subsist and work in the lebensraum that would normally be assigned to one of them alone, but it is not a happy demonstration.

In his last report in 1945, he predicted utter chaos unless a new library building were soon provided:

The jigsaw puzzle is a modern invention. Sir James Murray in his well known dictionary tells us that the word jigsaw came from the United States ... this should surely minister to our national pride . . The Labyrinth and maze, from Minoan Crete to Hampton Court, have cast their fateful or their comical shadows over the whole race of man.

Such a sinister shadow, with no comical aspect to soften its threat of woe, is beginning to rest upon Cornell University Library. An original logical and intelligible order in the housing of its books is being gradually turned into a jigsaw puzzle and a labyrinth by the dire pressure of dwindling and exhausted housing and working space. ... Only the more refined jigsaw intelligence can succeed in keeping track of the incongruously jumbled shelving system. . . . It matters not how many young men and library maidens are sacrificed to propitiate the monster. The Minotaur will eventually crush us all or drive us into the mad house.

The situation was incredibly bad, and it is understandable that the administration and staff of the library, tired out by the many years of unsuccessful struggle, would not spend their meager resources on reclassification. It was a miracle that the library continued to operate as a living institution which was giving valuable service to the Cornell community. This achievement was possible only because of the almost unbelievable loyalty of the staff. It had been Cornell's great fortune to be served by a number of librarians whose utmost devotion to their beloved institution has rarely been equalled in the history of American university libraries. The associate librarian, E. R. Willis; Emma R. Speed, catalog department; Elizabeth Ingersoll, acquisitions department; Lillian Leland, periodicals and binding, and others equally devoted, kept the library going. They were not successful in obtaining a new building, but they had not fought in vain. Without their heroic resistance we, their successors, could not have gained victory. Dr. Kinkeldey and his loyal coworkers may well take consolation in the Latin adage, "Victrix causa diis placuit, victa Catoni."

In the fall of 1946 a new and more felicitous era started for the Cornell University libraries. S. A. McCarthy took over the directorship, and under his administration the library has regained the eminence it enjoyed in the nineteenth century. Dr. McCarthy received many promises from the university administration-and a little help; it was not too much, but it was enough to enable him to increase the staff slightly, allowing him to make a few new key appointments for instance, the first full-time reference librarian Cornell has ever had. Of cardinal importance for the question of reclassification was the library survey which the trustees authorized for the fall of 1947. Louis R. Wilson, R. B. Downs, and M. F. Tauber studied the Cornell University libraries in every detail and submitted an exhaustive report of their findings and recommendations.

Dr. Tauber, America's foremost authority in the field of cataloging and classification, was requested to make a special study of Cornell's classification. His adverse opinion of the Harris classification has been quoted here, and he strongly advised discontinuing forthwith this oldfashioned procedure which was not only totally inadequate but also very expensive. In order to be prepared for all ar- 
guments, Tauber discussed briefly the possibilities of "modernizing" the Harris classification and making its application less cumbersome. Such a patchwork would entail at least five steps:

1. Edit and reproduce the 117-page manuscript classification schedules

2. Prepare a detailed subject index to these schedules

3. Introduce an effective author-numbering system

4. Prepare a card shelf-list record from the existing book records

5. Make necessary adaptations of schedules

He estimated that these preliminary procedures would cost at least $\$ 90,000$. Very little would be accomplished by the expenditure of this large sum of money; operational costs would remain high, and the many inconsistencies of the classification would not be remedied. Thus, to say it bluntly, it would have been money down the drain.

The second choice to be considered was that of restricting Library of Congress classification to all new acquisitions and leaving all books bought before December 1947 in the old arrangement. Tauber did not favor this solution (neither did we) because it would have relegated more than eight hundred thousand valuable publications into a limbo, at least as far as use was concerned. It would have destroyed the unity of the subject collection, impaired browsing in the stacks, and caused continuous processing difficulties and delays with monographs in series, with continuations, and with added copies.

Not everyone, however, agrees with our viewpoint. Many years later, when our reclassification was in full operation, a German librarian visited Cornell. I showed him with great pride what we had done, but our colleague from overseas put ice-cold water on my enthusiasm by remarking that most German librarians would have preferred the second solution, which both the surveyors and the library staff had rejected almost out of hand. His argument was that we had missed an almost ideal opportunity to make a clear chronological break between the old and the new collections. It was not his belief that these two collections should be integrated, but rather that they should be shelved and catalogued as separate entities. Although I can see the many valuable points in his argument, I still believe, many years post factum, that we have made the right decision. As we are continuously acquiring older publications, the purchase date would not have given us a distinctive chronological division unless we were prepared to classify the older material under the Harris classification and thus, continued to process two classifications ad infinitum. I readily consent to have a separate collection in a compact storage arrangement (most larger libraries have accepted this by now), but in this case the division is based on value (or frequency-of-use) judgment and not on the imprint or purchase date. In all circumstances, I would be very lukewarm about giving up the unifying function of the catalog unless the size of the catalog reaches such proportion that it becomes unmanageable.

However, regardless of whether these arguments are right, the decision in 1947 was unanimous in disapproving such an arrangement as outlined above, and we turned with much greater interest to Tauber's third alternative. He proposed using the Library of Congress classification for all new purchases, combined with a limited reclassification and recataloging program involving about two hundred thousand volumes at an estimated cost of approximately $\$ 150,000$. He suggested the following subject areas for reclassification:

Subject Areas

Number OF VOLumes

Italian Literature ............... 4,000

Spanish Literature ............... $\quad 3,000$

French Literature $\ldots \ldots \ldots \ldots \ldots \ldots \ldots, \quad 5,000$

American Literature ............. 9,000

(Continued on page 440)

COLLEGE AND RESEARCH LIBRARIES 


\section{Cornell's Reclassification ... \\ (Continued from page 374)}

English Literature ............... 35,000

General Literature ............... 5,000

German Literature ............... 9,000

Slavic Literature ................. 1,000

Music ....................... $\quad 3,500$

Fine Arts $\ldots \ldots \ldots \ldots \ldots \ldots \ldots \ldots, 10,000$

Agriculture $\ldots \ldots \ldots \ldots \ldots \ldots \ldots \ldots .4,000$

Bibliography and Library Scicnce ... 4,000

Anthropology .................. 1,000

Sociology $\ldots \ldots \ldots \ldots \ldots \ldots \ldots \ldots \ldots, \quad 6,000$

Economics ...................... 30,000

Engineering (Inclustrial Arts,

Military Science) $\ldots \ldots \ldots \ldots \ldots \ldots .14,000$

American History ................ 16,000

Philology . . . . . . . . . . . . . . . . 22,500

World War II ................. 1.000

Local History . . . . . . . . . 20,000

Far Eastern (except Wason) ........ 3,000

United Nations (includes part

of International Law) $\ldots \ldots \ldots \ldots \ldots, 2,000$

Psychology ..................... 2,000

Total (est.) $\ldots \ldots \ldots \ldots \ldots \ldots, 200,000$

The fourth proposal envisaged the reclassification of the entire collection of slightly

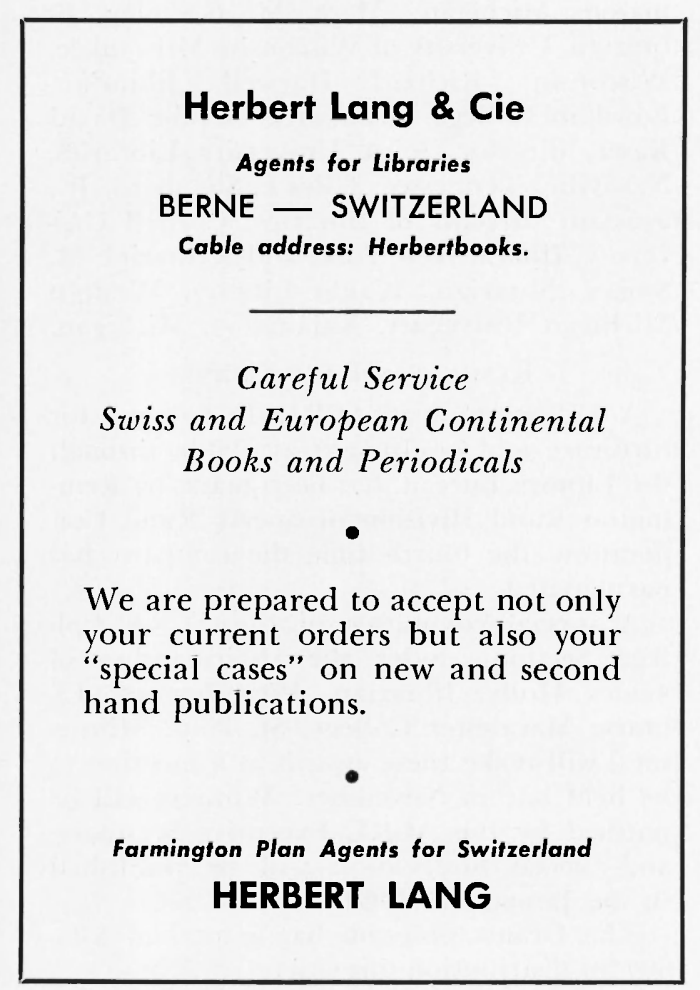

over eight hundred thousand volumes at an estimated cost of about $\$ 600,000$, to be achieved in a period of twenty years. Dr. Tauber favored this plan because a complete reclassification and recataloging of the collection would modernize the card catalog, replace lost and soiled cards (many were still handwritten), and provide an up-to-date inventory. He realized, however, that the university might not be able to provide such a large sum of money. The survey, therefore, recommended:

That the Library of Congress method of classification be adopted for all new books added to the collection of the university library.

That the reclassification of certain selected sections of the present collection as listed be accomplished over a period of years; and that a sum of approximately $\$ 150,000$ be provided for this work.

That such recataloging be done as is necessary to correct the inaccuracies and inconsistencies which now appear in the general catalog of the University Library.

The library board voted approval of the change to Library of Congress classification to be effective January 1, 1948. With regard to reclassification, it was decided that the operation should be started at a later (not specified) date, and that every effort should be made to procure $\$ 150,000$ either from the university administration or from some foundation.

This decision had to be amended as classification is only one part of the cataloging procedure. In order to take full advantage of the cataloging done by the Library of Congress, it was agreed to accept the descriptive and subject cataloging of the Library of Congress without any changes except for the author Cuttering. This policy would increase the speed of our operations to a marked degree and bring us in line with modern procedures. It would, however, cause almost insurmountable difficulties in another aspect of our work; whereas we could easily interfile entries based on two classification methods with different notations, we could not combine two subjectheading systems with diverse terminologies. Cornell's subject headings were very scholarly, with a distinct leaning toward Latin 
phraseology; the modern terms were frequently in vernacular and gave preference to everyday usage. For instance, we were using "Unitas Fratrum" for the Protestant denomination commonly known as "Moravian." It would have been feasible to bridge the gap between the two terminologies by an elaborate system of double cross references, but then we would perpetuate a clumsy catalog. Moreover, with respect to reclassification and our decision to modernize the catalog both in system and in appearance, it was much better to distinguish clearly between the old and the new.

The decision was made to start a new catalog in 1948. Many of us were unhappy about the idea of having two catalogs. We could foresee that the necessity of having to check two places would cause difficulties, annoyance, and mistakes both for the patrons and the staff. However, none of us could come up with a better proposal. Dr. Tauber, who participated in our discussions, spoke very strongly in favor of a new catalog, and today we acknowledge gratefully that he was right. We are happy that we followed his advice and were guided by his sage counsel.

In the meantime, partly preceding the survey and independent of it, great changes had taken place in the administration of Cornell's technical operations. The purpose of the reorganization was the elimination of double handling (doing one operation twice under slightly different aspects) and the integration of the acquiring and recording processes. Every step was worked out in all details in order to guarantee the smooth flow of books from selection to their placement on the shelves with all cards filed in the catalog. The final solution was graphically illustrated in a carefully designed flow chart.

The cardinal element in our plan was the transfer of the pre-cataloging operations to the searching section of the Acquisitions Department. It stands to reason that no search is reliable unless it follows the form of entry used in a given library. The searcher, therefore, received clear instruction as to how to establish an entry and how to verify it. Almost without loss of time, all the other information needed for pre-cataloging could be added to the search slip: Full name of a uthor, dates, Library of Congress card number, verification found in bibliographical tools, series-if any, Cornell holdings for the author or title with classification, etc. The search slip travelled with the book and supplied practically all the information the cataloger needed.

The plan was theoretically a sound one, but we soon encountered a major difficulty. The professional cataloger was very reluctant to accept the information provided by an "outsider" and to trust the judgment of a noncataloger. Such reluctance to accept the searching information at face value without rechecking it (a primary condition for speeding up the work) was partly based on the fully justified recognition of the difficulty inherent in good cataloging; partly, however, it was a defense of the intellectual status of the cataloger. A workable solution had to take both aspects of the problem into account. It had to correct the factual shortcomings and had to supply a psychological redress to what was, in part, a morale problem. Our answer was to appoint a senior cataloger as associate acquisitions librarian in charge of all searchers, with the assignment to correct and revise all search-slips before forwarding them to the catalog department. This solved most of our difficulties and up to now, by unwritten statute, the position of associate acquisitions librarian is reserved for a librarian who has been a senior cataloger at Cornell. For all professional appointments in the acquisitions department preference is given to a Cornell cataloger, and an intimate knowledge of the Cornell cataloging manual and several months training in the catalog department is obligatory for the entire professional staff in the four technical service departments.

This reorganization contributed greatly to the speeding up of processing operations and to making our reclassification program possible. Especially during the first seven years when we had no reclassification staff, the searching section verified all entries which had been selected for reclassification and supplied the necessary bibliographical information-Library of Congress card number and Cornell holdings.

Another innovation was the abolishment of a separate classification division. The intricate system of the Harris classification had compelled the library to concentrate this aspect of the work in the hands of one person. It would have heen extremely difficult 
to train the entire cataloging staff in the application of a method which came very near to being unteachable. Moreover, it would only have compounded existing confusion. With the acceptance of the Library of Congress classification, these conditions no longer existed. The rather incongruous split between subject headings and classification could be avoided; only one revision would be necessary and, therefore, the individual cataloger was made responsible for all phases of the work.

As early as July 1947 , four months preceding the survey, a coordinator of the technical services had been appointed in order to work out a complete overhaul of the operations. In January 1948, following the survey recommendations, the division of the technical services was established with an assistant director in charge.

Thus, we were all set to start a new chapter in the life of Cornell University library. However, before we could think about this joyous event, a lot of preparatory work had to be done. All cataloging was stopped for the last two weeks in December and for the first few days in January, except for a few rush titles, and all work which had been in progress, including card production and filing, was cleared up. About forty thousand cards which had been withheld from the cata$\log$ because a variety of corrections had to be made were filed. The entire staff of the library, regardless of administrative position or departmental assignment, participated in the effort to clear our decks before the hard battle which we anticipated.

Punctually, according to our planning, the operations went into effect on our miniature "D Day." Books were processed under the new rules and the new "baby" catalog was started. Reclassification was officially scheduled to begin at a later date when the funds necessary for this operation would have been provided. However, we just could not wait until this date which seemed to be in the Utopian future; circumstances of every day operations forced us into action, and we had to start reclassification willy nilly.

From a realistic point of view, it was utterly wrong to spend staff time on reclassification. Our first priority was undoubtedly

\section{ИЗВЕСТИЯ}

\section{А А ДЕМ ИИ ИА У ОТДЕЛЕНИЕ ТЕХНИЧЕСКИХ НАУК}

МЕТАЛ У РГИЯ И ТОІІ ЛИО

RUSSIAN METALLURGY AND FUELS

A publication of the Academy of Sciences of the U.S.S.R., Department of Technical Sciences, this journal presents the results of recent investigations at Soviet research institutes on the subjects of extraction metallurgy, ferrous and nonferrous metallurgy, and solid and liquid fuels.

English version of January/February 1962 issue now available. Annual subscription $\$ 68.00$. From the publisher or through any subscription agent.

Scientific Information Consultants Ltd., 661 Finchley Rd., London N.W. 2 England 
the processing of the flood of new acquisitions which was the result of a rapidly increasing book budget. We had no elbow room in the stacks which would take care of a voluminous reclassification, we had no money to hire new staff-and we did not have the place where we could put them to work. The deadlock of the reclassification program only mirrored the difficulties of the library as a whole. We did not have the full-hearted and enthusiastic support of the Cornell community because we had not given all the service it wanted; we could not give the service unless we had more money, and we could not get financial support unless we satisfied the demands. Should we spend our best years just waiting for someone to make the first move? This seemed pretty hopeless. Thus, we decided to take the first step. In other words, we decided to deliver the goods; we would satisfy the demands and hope that sooner or later we would receive the support we needed. This was the right decision, although it meant some hardship, and it took longer to get the full support that we had expected in January 1948.

Some figures will illustrate our difficulties. Thirteen years later, January 1961, before we moved into the new Olin Research Library, the harassed circulation department had to find space for a book collection which more than tripled the full capacity of the old library, the book budget was ten times the amount available in 1947, we had greatly increased the staff, and the reclassification program was in full course.

It had not been easy; there were times when we seriously considered working in night shifts, and we jokingly stipulated maximum weight and rotundity for the staff in order to pass through the aisles which became narrower and narrower. However, we all survived in good health and did not go mad as Dr. Kinkeldey predicted. Surely, we worked hard and in rare circumstances tempers were short, but we did not pull knives and, in spite of being in western New York, we did not live in a frontier atmosphere.

We could not avoid reclassification in case of added copies and added volumes for titles in continuation. Even if we had wanted to adhere strictly to the decision of the library board, neither the state of our cataloging records, especially the shelf list in book form, nor the overcrowded shelves would have permitted us to add thousands of volumes to the "Harris classification. But quite frankly, we did not want to; we were most eager to get on with the reclassification; the small size of the new catalog served as a continual challenge and almost as a reproach. New acquisitions were processed promptly, and no backlog was permitted to accumulate; but every staff member who could be spared even for a short time was put into reclassification.

We would have liked to reclassify simultaneously all editions of a given title or even, if possible, all works of a multi-volumed author. This, however, was not possible for many years to come and caused much annoyance and justified criticism. We reclassified selected volumes which were being sent to be rebound in order to avoid a second handling of the volumes at a later date and the erasing of the Harris notation. We could not do everything, especially in the first seven years, not even all one-volume monographic titles, not to speak of volumes which were parts of a larger set. As it always is in life, lack of money forced us to policies which were more expensive in the long run. The reclassification of periodicals was a case in point. The library had at that time a little over three thousand subscriptions, but even this number (much too small for a research library) was far too big for a reclassification program without staff. We had no choice but to add the complete volumes to the old Harris numbers although every effort was made to diminish the number of "Harris volumes."

A similar "expensive economy" was applied to the reclassification of large periodical sets. Out of reasons of economy, we had decided not to reclassify larger sets of periodicals and we established an arbitrary limit of five, later ten, volumes which would make a set eligible for reclassification. For the larger sets, we did the necessary recataloging and included the titles in the serials catalog but did not touch the classification. In all these cases, some duplication of work had to be performed when we decided years later to reclassify the entire collection.

Reclassification, even at its earliest stage, could not be limited to a random selection. Some collections had become so unusable under the old system that an immediate reclassification had to be done lest we impair 


\section{The Definitive Index}

\author{
of the entire \\ aerospace field
}

\section{THE PACIFIC AEROSPACE LIBRARY UNITERM INDEX}

finds the exact technical material you want from more than 300 English language scientific periodicals covering:

aerodynamics $\cdot$ missile design $\cdot$ rocketry $\cdot$ astronautics $\cdot$ nuclear physics - metallurgy $\cdot$ communications - data acquisition and processing $\cdot$ mathematics $\cdot$ radar $\cdot$ computers $\cdot$ physics - automation - electronics - physical chemistry $\cdot$ aviation medicine $\cdot$ plastics - ceramics - ordnance - production $\cdot$ management

Material is located rapidly with pin-point accuracy. Sources include translations of Russian journals and other publications of worldwide scope.

The UNITERM INDEX is unique in its field; more than $50 \%$ of the periodicals indexed do not appear in any other cumulative index. It is not bulky, complete in its binder it weighs only $31 / 2$ pounds.

One Year's service-cumulated bymonthly

$\$ 250.00$

obtainable from

\section{PACIFIC AEROSPACE LIBRARY OF THE INSTITUTE OF THE AEROSPACE SCIENCES}

7660 Beverly Blvd. Los Angeles 36, California some of the most important service functions of the library. The reference collection was chosen as first target because its arrangement was most unsatisfactory from every point of view. The collection had originally been classified under the Harris system like the rest of the library. In the late 1920's the Library of Congress classification, greatly modified and generally limited to the main classification letters, was superimposed on the old notation. This double classification caused great difficulty when titles were transferred back to the stacks. Thus, fifteen years later, part of the "schismatic" Library of Congress notation was removed with the result that the arrangement followed no discernible system.

And so the first years passed with no financial support in sight although annual reports reiterated the warning that no significant progress could be expected unless budgetary help were given. Thrown back on our own resources we tried to substitute streamlined operations for additional staff. We had encountered some difficulty in discharging reclassified volumes from the circulation record. The circulation file was kept under the old Harris number and the cataloger had to insert a flier in the reclassified volume and pencil on it the old Harris notation. This was time consuming and led to errors. We developed a double circulation request with an inset carbon paper; one part was interfiled in the circulation record and the second part traveled with the book, facilitating the discharge.

A device which bore directly on the speeding up of processing was an arrangement for storage by size. It had occurred to us that some of the titles which we had to reclassify did not need a double subject approach, by classification and through subject headings. Moreover, we did not want to clutter up our new shelves with books which would only impede browsing and which, if needed, would probably be requested by author and title. Some examples of this category of books are: older editions, obsolete monographs, the majority of dissertations, etc. We refrained from giving a rigid definition based on date of publication but insisted that every title be judged according to its textual or typographical merits. Only as guidance for the selector (senior staff member or subject specialist from the teaching faculty) we specified 1920 for science and technology, and 1850 for 
the humanities and social sciences. The research obligation of the library induced us to preserve all works of possible historical significance, but duplicate copies were discarded. Thus, as an unforeseen fringe benefit of reclassification, we accomplished a longoverdue weeding of the collection.

Books chosen for compact storage were arranged according to six sizes and Cuttered with current numbers. Rules for descriptive cataloging were strictly adhered to, but especially long titles were abbreviated. Greatest economy was applied for subject headings and added entries.

The greatest advantage for our task was the establishment of a serials department. The group was charged with the upkeep of the serials catalog and with the processing of all commercial serials. Later on, document serials were added to its responsibilities. Under an energetic and resourceful head, the department reclassified within a few years all active serials which fell under our restricted reclassification program.

The great increase of output in the cata$\log$ department caused difficulties for card reproduction. Whereas in the ancien regime we had processed a little over ten thousand titles annually, we reached in the early 1950's an average of thirty thousand titles, six thousand of which were due to reclassification. We used Library of Congress printed cards whenever readily available, but more than half of the cards were locally produced. The combination of xerography and multilith machines (November 1954) gave us the tools to produce the needed quantity.

Thus, like Jacob, we had faithfully served seven years in the hope of getting a special appropriation for reclassification. By the end of the fiscal year 1954/55, we had reclassified 102,789 volumes or a little over fifty thousand titles. So, without any help whatsoever, we had carried out one half of the limited reclassification program suggested by the survey in 1947. Mere figures, to be sure, are somewhat misleading, as we had not really fulfilled 50 per cent of the assignment. Dr. Tauber had chosen the most important and widely used classes of publications, whereas we had been forced to deviate from his wise plan and to reclassify a much more diversified, sometimes random, and at times less important selection. Still, our performance was nothing to be sneered at, especially consider- ing the fact that by now the cataloging of new titles had tripled the annual production of the old Harris days. Like Jacob we did not receive Rachel (an appropriation commensurate with our goal) but had to be satisfied with her less attractive sister Leah.

Dr. McCarthy's persistent attempts to obtain financial support for our program finally resulted in a special appropriation of $\$ 10$,000. This item first appeared in the budget for 1955-56, was renewed and slightly increased in the general rise of salaries that followed, and represents today a financial value of $\$ 13,000$. We decided to appoint a reclassification team of one professional and two clerks, the professional to be a cataloger of senior standing who could work, unrevised, assisted by a subprofessional who would pull the cards from the old catalog and do easy cataloging. The third member of the team was under the administrative supervision of the other sections of the technical services and assigned to perform various auxiliary operations such as marking, typing, alphabetizing, and filing. This organization proved to be quite a satisfactory one, and we maintained it throughout the second seven years of our program. Reclassification, however, was not confined to the work of the team, and the regular staff of the catalog department reclassified, as before, all the titles of which we acquired added copies, added volumes, or new editions. In all these cases, the acquisitions department pulled the old cards and established the new entry and the Library of Congress card number.

The financial support we were receiving and the increased confidence in our own potentialities changed our outlook toward the program, altered its goal, and modified some of our procedures. If I may revert a moment to my analogy of Jacob's labors, we had no intention of giving up Rachel regardless of how many years of hard work Laban should demand. We were convinced that partial reclassification was not the answer. Nothing less than a complete modernization, without exceptions, without islands of obsolescence, would satisfy us. In our flight towards the goal of total reclassification, from a realistic point of view (still a Utopian one), we had reached a point of no return. It was not possible for us to go back; the arguments of Dr. Tauber presented to us in the fall of 1947 were still relevant. The two catalogs could 
never be combined; the Harris classification was still utterly unsatisfactory and should not be maintained. We had been able to complete half of the limited program without any help, we were therefore convinced that we could finish the entire project with some assistance. The experience of the last years had borne out our belief that we were on the right way and that the university was prepared to give us the support we needed after we had made the first steps unaided. We decided, therefore, to accept as our goal the reclassification of the entire collection, even including periodicals and documents; this meant, of course, that the old catalog would be eliminated in due course and that the library would again have only one cata$\log$.

This decision had several implications. For instance, the ban of reclassifying larger serial sets (more than ten volumes) was rescinded. The work done by the serials department during the last years could now be used advantageously. Many sets had been recataloged and had been entered in the new serials catalog. The Library of Congress classification had to be established, but otherwise no changes had to be made in the entries, cross references, and checking-in cards. In a skillfully planned operation jointly administered by the serials librarian and the periodicals librarian, using evening hours and student help, many thousand volumes were speedily re-marked.

The additional manpower available enabled us to apply more efficient procedures and to follow more closely Dr. Tauber's selection of classes. It is far more advantageous to select a homogeneous number of books from the stacks than to reclassify the diversified groups of titles chosen because of the random acquisition of added volumes. The cataloger remained within a narrow classification and could often, especially in the literature classes, concentrate on one author. The circulation department was notified of a block of Harris numbers which were being reclassified and individual reclassification slips could be omitted. Unfortunately, the crowded stacks and frequent

\title{
- To Facilitate. Your Research -
}

\section{Annual Legal Bibliography}

A world-wide subject index to books and articles

\section{Current Legal Bibliography}

A selective monthly supplement, October to June
American Law

Foreign Law

Comparative Law also

Political Science

History

Economics

Government

Subscription to complete service, $\$ 15.00$ annually.

Order through your agent or directly from:

\author{
HARVARD LAW SCHOOL LIBRARY \\ Langdell Hall \\ Cambridge 38, Massachusetts
}


shifting of sections would not permit us to stay too long with a given class of books. The selection for reclassification could not be made solely from the point of view of importance and use but had to yield to a frequently-crazy system of shelving which inadequate space forced on a suffocating circulation department.

In the case of random reclassification, too, we could now reduce the heavy pressure the reclassification program had put on the circulation department and could cut down on annoying delays. In many cases the circulation department had not been able to supply promptly all the titles requested for reclassification as many volumes had been lost during the last scores of years and some had been mis-shelved. Previously, the circulation department had embarked on a laborious and time-consuming searching procedure which took at least three to six months until a book was declared "lost." The new regulation simplified this procedure. The report that a book was not on the shelves and did not appear in the circulation record was checked once by a senior member of the shelving staff; a corresponding note was made in the 'Harris shelf list' and the cataloger was advised to proceed with the volumes at hand. The underlying assumption was that in the total reclassification the mis-shelved volume would turn up sooner or later. In spite of this possibility, we replaced important titles as soon as possible. This meant, of course, that we might acquire duplicate volumes in a few cases, but as we confined replacement to important and much-needed titles such duplication would not be harmful.

We also eliminated copying the accession number which, under our old procedure, had been noted on the verso of the main entry and on the shelf list. In the case of serials, we had dispensed with this operation long before. We now dropped it for the entire project. We realized that the accession number could be very helpful for the identification of a given copy, but this petty benefit did not justify maintaining a time-consuming and obsolete procedure.

After three and one-half years of working with one reclassification team, we had made a significant dent in the old holdings. The completion of the project, however, was not even in sight and we did not cherish the prospect of having the Harris classification conspicuously represented in the stacks of the new Olin Research Library, the construction of which had just started. In a casual lunch conversation our dilemma was mentioned to Paul McKeegan, the director of the budget of the university; in addition, the information was volunteered that another university library had just received a considerable appropriation for its reclassification project. Mr. McKeegan understood the hint and recommended to the president that the library be granted financial assistance to speed up reclassification. To our delighted surprise, the board of trustees approved an allocation of $\$ 105,000$ on January 21,1959 . $\$ 100,000$ was allotted for three years' salaries for three reclassification teams, and $\$ 5,000$ was earmarked for the purchase of furniture and equipment.

A small but smoothly working reclassification section was established, headed by a capable senior staff member of the regular catalog department. Her staff consisted of four catalogers-only one had senior rank, two were recent library-school graduates, the fourth a former subprofessional in the Cornell catalog department who was promoted to professional standing because of her ability. The group was most efficiently assisted by four subprofessionals, young ladies who had had no formal library training and little library experience, but who had been selected because of their intelligence, willingness to work, and general aptitude. Three additional clerical staff members, who could be paid from the reclassification project, were assigned to the regular catalog department to perform the many auxiliary operations made necessary by reclassification.

Because of salary savings we could augment the staff with five college graduates during the two summer months. Although none of this delightful group of young women had any library exerience whatsoever, they made a substantial contribution to our effort because of their eagerness to work, willingness to learn, and general high intelligence.

It was not possible to find working space for the reclassification section in the overcrowded cataloging room. A small adjacent stack space had to be converted into a work 
area, although this, of course, compounded difficulties for circulation. There were a few complaints about temperature and ventilation, but on the whole this makeshift arrangement worked well for the two years we occupied it.

In the plan of operations submitted to Dr. McCarthy the annual production goal was set as fifty thousand titles or seventy thousand volumes. The expectation was that every one of the four teams would reclassify ten thousand titles and that the regular catalog department would account for the rest. Alas, like other noted five-year plans, our modest three-year plan did not quite reach its goal. We had been too optimistic in our estimate and never reached the fifty thousand mark but hovered around forty thousand titles or sixty thousand volumes annually. The four reclassification teams made their quotas, but the general catalog department could reclassify only a couple of thousand titles annually, as it was critically weakened by delegating one of its best staff members to administer the reclassification section. It had to struggle hard to keep up with the increased number of new acquisitions. (The production of new titles in 1958-59 was thirty-two thousand. The number climbed to forty thousand the following year, to forty-four thousand the next year, and will not be far below sixty thousand during the current fiscal year.)

The staff of the processing departments was fully conscious of the fact that every effort had to be made to increase the speed of reclassification as much as possible. We were, therefore, looking out for shortcuts which would help us in our endeavor. One of our most annoying and partly surprising stumbling blocks had been the removal of cards from the old catalog. Card removal is a tedious operation under the best circumstances; we labored under three additional difficulties. Many older entries had no tracing and we had to guess the subject entries which had been made; different editions were combined on one subject card, and the cards were filed too tightly. According to our experience, it took between five and twenty minutes to remove a full set of cards. Three

\title{
CUSHING-MALLOY, INC. \\ 1350 North Main Street P.O. Box 1187 \\ Ann Arbor, Michigan
}

\section{Printers of ACRL Monographs}

\section{I T H O P R I N T E R S}

Known for

QUALITY-ECONOMY-SERVICE

\author{
Let us quote on your next printing
}


cards were of immediate use: one was filed as "in process card" in the new catalog, the second one was treated as a temporary shelf card and the third one was utilized as the basis for the new entry; the rest of the set was discarded. Dr. McCarthy was strongly in favor of a radical solution to this problem. He suggested that for the time being only three cards per title be removed from the old catalog and that the discarding of the rest of the set be postponed to a final mopping-up operation after the termination of the reclassification project. We all agreed that the crash program called for a reconsideration and redefinition of all our operations, but there was some reluctance to weaken so drastically the reliability of the old catalog. The new regulations set a limit of five minutes of card removal per title. The rest of the set (if any) remained in the old catalog. Every shortcut causes slight difficulties at times but experience over the last year has proved that our fears had been groundless. Neither technical operations nor reader services were hampered by incomplete withdrawal of cards from the old catalog.

We discontinued marking the Harris shelf list with the new Library of Congress number but used a rubber stamp to indicate that the title had been reclassified. The Library of Congress depository catalog was placed in the reclassification work room so that the cards could be used without delay. In the case of analyzed series, however, we found it more advantageous to disregard the depository cards and to order full analytics from the Library of Congress Card Division.

Reclassification was concentrated on those classes of books which were most heavily in demand. The first target was American and English literature, and over forty thousand volumes were reclassified in the first eight months of the new program. The work was coordinated with the assignments given to the rare book cataloger and to the serials department in order to cover all our old holdings in these fields. Then attention was shifted to American history, including both Canada and Latin America. During the rest of the period, most of the social sciences and the humanities, with the exception of classical philology, was cleared. Special care was taken that the assignments to the four teams would not overlap, so that every staff mem. ber had sufficient elbow room. Two groups of titles were reclassified without regard to the subject field, the work with analyzed series continued, and every book in "Harris" was reclassified which fell under one of the three categories: 1) returned by reader; 2) selected for rebinding or repair; 3) needed because an added volume or an added copy had been acquired.

Two-thirds of the time envisaged by Dr. Tauber for total reclassification has passed. During this period, the catalog and serials departments have reclassified and recataloged six hundred thousand volumes representing two hundred twenty-two thousand titles. According to a physical count made by the circulation department, two hundred twentyfive thousand volumes are still in the old classification. The present-day circulation statistic mirrors the fact that more than two million volumes (the bulk of the collection) are in Library of Congress classification. In the Olin Research Library, the use of Harris books (shelved in a part of the basement stacks) has dwindled to 11 per cent of total circulation, and in the department and college libraries it is zero, for these collections do not have books in Harris any longer. The new card catalog has 5,740 drawers whereas the old is filed in 770 . This statement, however, does not represent the true story; there are more cards in the old drawers than in the new ones; on the other hand, many of the older cards are blind cross references or subject cards which will be discarded in the final mopping-up operation.

Dr. Tauber had suggested the need of a special appropriation of $\$ 600,000$ to do the job. This was fourteen years ago; considering the general rise in costs, this sum would be much higher if calculated today. We have spent a special appropriation of $\$ 180,000$ to date, and with another $\$ 150,000$ we could easily finish the job within the period specified by Dr. Tauber. These figures obviously do not represent our real costs. The difference lies in the "surplus value" produced by a loyal and devoted staff.

From the very outset, reclassification was a project for the entire staff of the Cornell University library, and all departments have most generously supported the complex activities. It is impossible to name all those whose efforts have been essential for the 


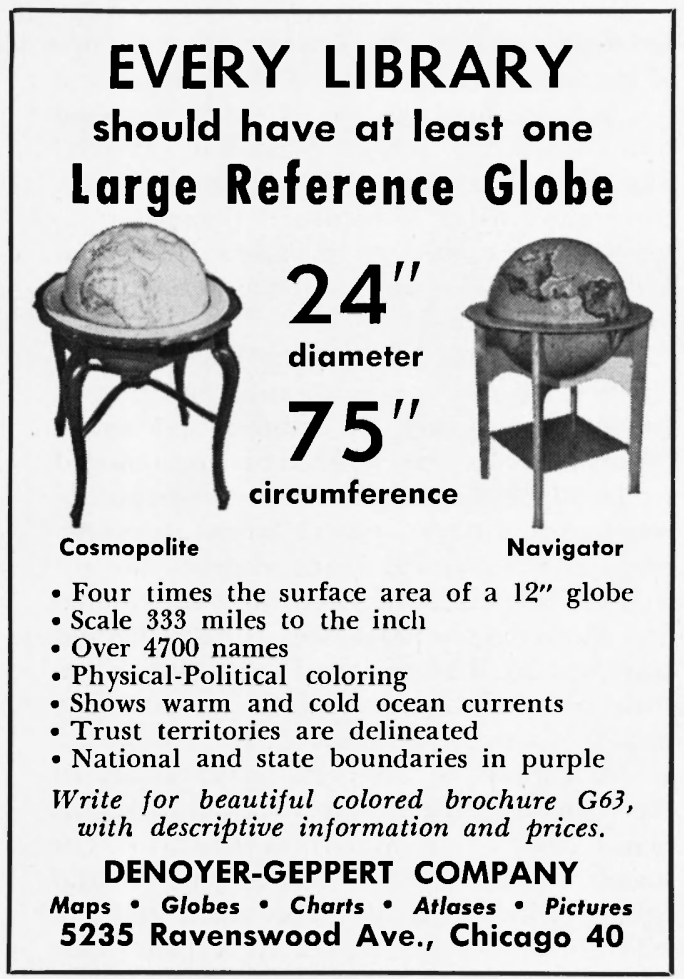

project; like the Unknown Soldier of our war memorial, they can be honored only in anonymity. Four persons, however, must be named because of the great contributions they have made: A. Elizabeth Crosby, head of the serials and binding department, responsible for the reclassification of all serials; Rosamond Danielson, supervisor of the reclassification section; Laura Jennings, head of the catalog department, and lastly, Emma $R$. Speed, the most faithful of all-a staff member of Cornell for forty-three years and head of the catalog department from 1925 to 1954. Trained in the old ways, she accepted loyally the new regulations, many of which must have been irksome to her.

It was the good fortune of Cornell University library that during the third phase of its institutional life it enjoyed the patronage of the president of the university. Deane Malott is keenly interested in library developments and has supported Dr. Mc Carthy's plans and recommendations. The Cornell University libraries, having survived the dark middle ages of insufficient support, can now enjoy the splendor of the Renaissance.

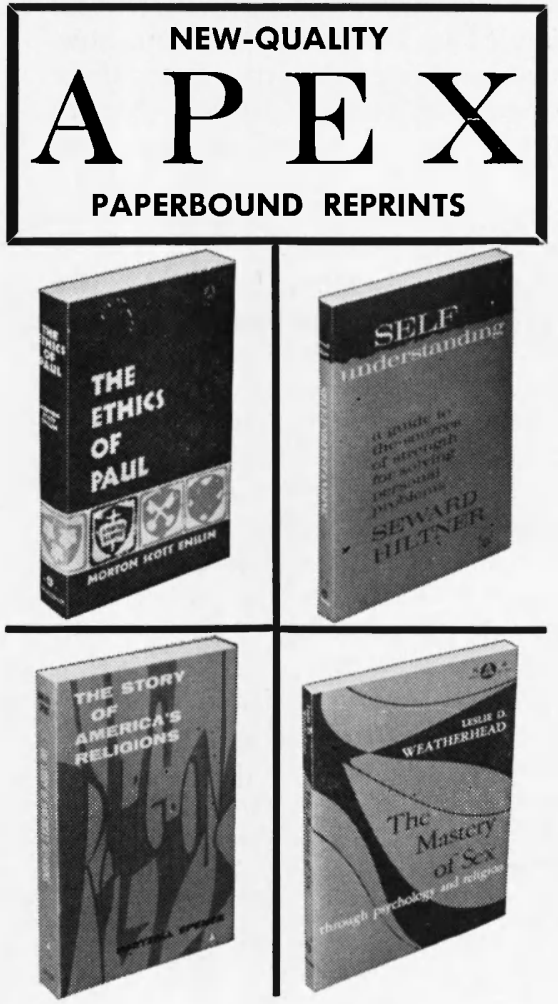

\section{The Ethics of Paul}

Morton Scott Enslin. A brilliant analysis of the ethics of Paul - the man who probably did more than any other to shape the moral standards of Christianity. 368 pages.

$\$ 2.25$

\section{Self-Understanding}

Seward Hiltner. An objective study of personality development. "A superior book ... one of the best in the field."Pulpit Digest. 240 pages.

$\$ 1.75$

\section{The Story of America's Religions}

Hartzell Spence. Here is the story of fourteen great religious faiths that have had a major impact on the American scene. First appeared in $L O O K$ Magazine. 272 pages.

$\$ 1.50$

\section{The Mastery of Sex Through Psychology and Religion}

Leslie D. Weatherhead. This book deals with sex problems of men and women by looking at these problems in the light of applied psychology and religion. 192 pages.

\section{A B I NGDON PRESS}

NASHVILLE 2, TENNESSEE

In Canada: G. R. Welch Company, Ltd., Toronto In Australasia: Thomas C. Lothian, Melbourne 